\title{
LUTI Model for the Metropolitan Area of Santander
}

\author{
Pierluigi Coppola ${ }^{1}$; Ángel Ibeas ${ }^{2}$; Luigi dell'Olio ${ }^{3}$; and Ruben Cordera ${ }^{4}$
}

\begin{abstract}
This article presents a land use and transport interaction model (LUTI model) to simulate the overall equilibrium of an urban system. The proposed system of integrated models combines random utility theory with hedonic regression techniques and a transport model with equilibrium between supply and demand to estimate the location of population, economic activities, and average real estate prices in different zones within an urban system. The LUTI model was applied to the metropolitan area of Santander (Spain) to check its base year goodness of fit and therefore its ability to predict the impacts of introducing different transport policies. In the case of Santander, the property price and population/economic activity location submodels showed sensitivity to the different accessibility and transport characteristics of each zone, and the model as a whole provided a good degree of fit. DOI: 10.1061/(ASCE)UP.1943-5444.0000146. (C) 2013 American Society of Civil Engineers.
\end{abstract}

CE Database subject headings: Utilities; Pricing; Spatial distribution; Equilibrium; Urban areas; Spain; Models.

Author keywords: Random utility models; Hedonic price models; Activity/spatial distribution; Equilibrium; Accessibility.

\section{Introduction and Objectives}

Classic urban economic theory states that the accessibility conditions of different places are a key factor in explaining the location of the population and the economic activities in an urban system. This idea began in early studies on agricultural land use patterns by von Thünen (1826), which were later applied to urban spaces by Alonso (1964), Muth (1969), and Mills (1972). The theory is based on the existence of a trade-off between accessibility and occupied space that needs to be resolved by the different urban agents. Thus, the locations with better access to the Central Business District (CBD) will have, ceteris paribus, higher population and activity densities, as well as higher land rents per unit area.

One of the consequences of this theory is that improvements in accessibility may increase the attraction of an area for people and economic activities as well as increase real estate value. However, other factors contribute to the complexity of urban systems. Fujita (1989), for example, provides a comprehensive exposition of urban location theory and considers the existence of a third essential factor, which is the presence of positive and negative externalities caused by certain environmental conditions such as public goods, high population densities, and traffic congestion among others.

${ }^{1}$ Professor, Dept. of Enterprise Engineering, "Tor Vergata" Univ. of Rome, Via del Politecnico 1, 00133 Roma, Italy. E-mail: coppola@ing .uniroma2.it

${ }^{2}$ Professor, Departamento de Transporte y Tecnología de Proyectos y Procesos, Universidad de Cantabria, Av. de Los Castros s/n, 39005 Santander, Cantabria, Spain. E-mail: ibeasa@unican.es

${ }^{3}$ Professor, Departamento de Transporte y Tecnología de Proyectos y Procesos, Universidad de Cantabria, Av. de Los Castros s/n, 39005 Santander, Cantabria, Spain (corresponding author). E-mail: delloliol@ unican.es

${ }^{4}$ Researcher, ETRA Norte S.A, Santander, Spain. E-mail: corderar@ gmail.com

Note. This manuscript was submitted on August 8, 2012; approved on January 30, 2013; published online on February 1, 2013. Discussion period open until February 1, 2014; separate discussions must be submitted for individual papers. This paper is part of the Journal of Urban Planning and Development, Vol. 139, No. 3, September 1, 2013. (C) ASCE, ISSN 0733-9488/2013/3-153-165/\$25.00.
Land use and transport interaction models (LUTI models) have been designed to simulate these complex relationships, starting from assumptions similar to those of urban economic theory although adapting them to the conditioning factors of real planning situations. These models have traditionally been used to simulate the possible effects of introducing new policies and projects into existing urban systems and, especially, those related to transport (Foot 1981). LUTI models have therefore been used as a complementary tool to transport models that consider a fixed pattern of mobility demand location and are, therefore, more adapted for making shorter term predictions (Ortúzar and Willumsen 2001).

The research presented here develops an integrated model to evaluate the interaction between land use and transport, which includes the structure developed in the STIT (System of mathematical models for the simulation of land use and transport interactions) model (Nuzzolo and Coppola 2005) and an exogenous real estate price model based on hedonic pricing theory. STIT is a LUTI model developed by Nuzzolo and Coppola $(2005,2007)$ with a similar structure to the Lowry model, combining economic base theory as an explanatory factor for the dynamics between employment and population with spatial interaction theory, as it considers location patterns as dependent on the cost of transport between zones. The model also incorporates random utility theory as a choice prediction model for the agents involved (companies and households), which provides STIT with a stronger base as it can be supported by microeconomic theory. The solution system for STIT can be characterized as that of a static equilibrium model. Any change occurring to an element in the territorial system (e.g., the transport subsystem) leads to a new equilibrium solution expressed by the new state of the system. The comparative equilibrium approach is currently the most viable when performing practical applications given the greater simplicity of these types of models during the calibration and implementation phases (Nuzzolo and Coppola 2005).

The developed LUTI model is made up of four interrelated submodels: a residential location submodel, an economic activities location submodel, a real estate price predicting submodel and a transport submodel. The four submodels interact through various information flows, mainly the indicators of accessibility and 
journey times between areas, to simulate the equilibrium of the urban system being studied.

The use of random utility theory in several of these submodels provides a solid microeconomic framework based on the maximization of utility by the agents involved compared with the analogies of gravity models based on aggregated data [Lowry model (Lowry 1964), DRAM/EMPAL (Putman 1996)]. The current STIT model is more complete as it is able to endogenously simulate average real estate values in the different zones of the study area. Finally, the land use model is completed by its interaction with a modern transport model, ESTRAUS, which is able to simulate the relationships between mobility supply and demand as a problem of simultaneous equilibrium (De Cea et al. 2003). This feature allows the model to simulate the workings of the urban system in a consistent way and at the same time consider the presence of network congestion, which previous LUTI models failed to do and sometimes tended to use transport models from outside the established literature (Wegener 2004).

The integrated system of models will be applied to a real case study, the metropolitan area of Santander (Spain), although it can be applied to any other study area. This practical application will then be used to check the model's goodness of fit with the aggregated and disaggregated data collected for the area.

The presentation of the research will be organized in the following way. A state of the art review will be presented about the field of LUTI modeling. This will be followed by an explanation on how the integrated system works, providing details on its overall structure and the composition of the different submodels. The study area being analyzed will then be introduced along with the data being used and the estimation of the parameters for each submodel. The model's goodness of fit to the base year data will be explained, and this will be followed by a series of conclusions.

\section{Bibliographic Review}

LUTI mathematical simulation models combine theory, data, and algorithms to provide an abstract representation of the interaction between the two main components of urban areas: the transport and land use subsystems (Torrens 2000). The first important theoretical contribution that elated transport and land use was made by von Thünen (1826) in the first half of the 19th century. Von Thünen related the agricultural land use system of an area with the costs of transporting goods to the central market. These contributions were later applied to urban areas by Alonso (1964) and in agreement with the von Thünen theory, were based on the existence of a single central business district (CBD) where all employment would be concentrated. Households and companies would therefore decide on their locations based on budgetary restrictions and their preferences when making the trade-off between accessibility and occupied space. Fujita (1989) provides an excellent comprehensive exposition of urban economic theory by considering the contributions made by a great many authors based around three basic location factors: accessibility, occupied space, and environmental conditions.

However, the application of these theories to the world of urban planning has not been without its difficulties, which has led to the development of a wide range of apt models for carrying out planning exercises but not necessarily coherent with economic theory. This phenomenon is what Harris (1985) referred to as the tensions between economic theory and the practice of simulation and planning.

Many models are currently available for carrying out simulation and planning exercises, and several authors have proposed classifications that group together different models according to diverse criteria. Wegener (2004) classified more than 20 models developed in the literature using nine main criteria: comprehensibility, structure, theoretical basis, techniques used, dynamics, data required, calibration, operationality, and applicability. Waddell and Ulfarsson (2004) made a classification based on the theoretical approaches that have appeared in the field of LUTI modeling over the last 50 years, whereas Iacono et al. (2008) classified the models found in the literature according to the historical development of the great theoretical paradigms of modeling. The typology presented below classifies the models in accordance with their basic theoretical nucleus and the chronological generation they belong to. Three generations and five basic types of models have been differentiated (see also Fig. 1).

1. First-generation models, the models that appeared during the 1960s and 1970s. They can be divided into three main types according to their theoretical basis for performing simulations. a. Spatial and gravity models based on the theory of spatial interaction or on the statistical mechanics generalization performed by Wilson (1970). The classic example is the interaction model developed by Lowry (1964), which was also supported by economic base theory for simulating

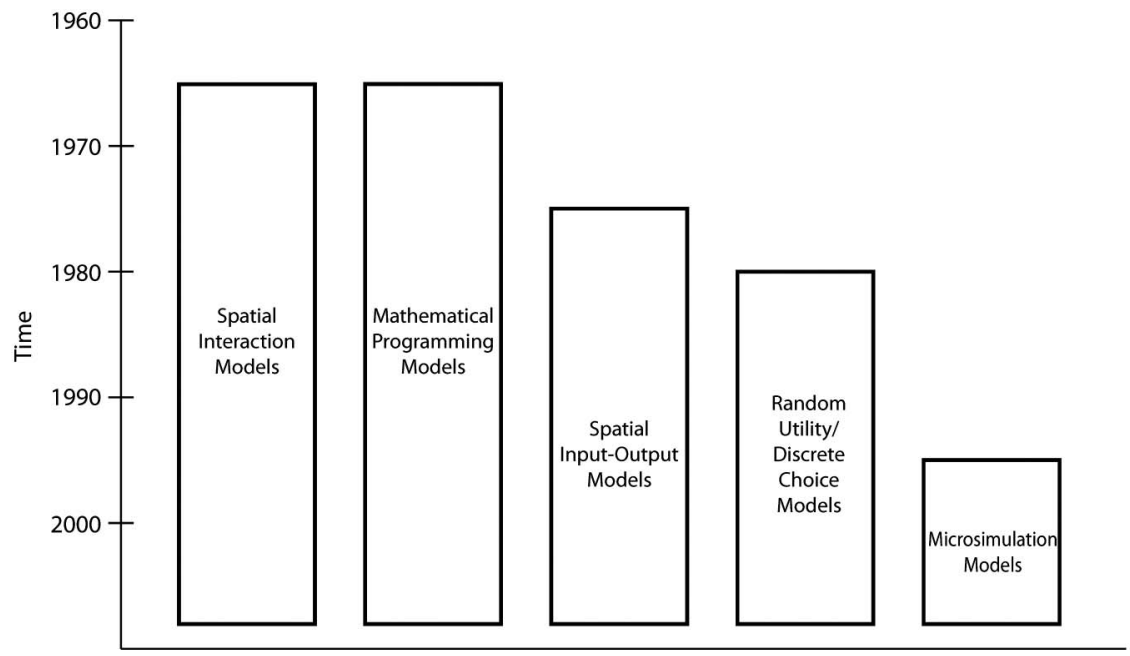

Fig. 1. Chronological development of LUTI models (Own elaboration based on data from Iacono et al. 2008) 
the locations of population and economic activities (Andrews 1953).

b. Mathematical programming models based on optimization techniques. This type of model is based on a simulation of agent behavior through the minimization or maximization of a certain objective. The classic model of this type was developed by Herbert and Stevens (1960) and simulated the operation of the residential location market following the theory of Alonso through maximization of aggregated rents. Another example of this type of model is TOPAZ (Technique for Optimum Placement of Activities into Zones), which determined the locations of activities as a function of the minimization of transport costs and urban development (Brotchie et al. 1980).

c. Models based on INPUT/OUTPUT matrices. This type of model simulates the urban or regional economy using the technique of input/output matrices developed from the work of Leontief (1966). An example of this type of model is MEPLAN (Echenique 1994, 2011).

2. Second-generation models appearing in the 1980s and 1990s. This type of model is based on random utility theory developed from the work of McFadden (1974). This generic type can be further differentiated into simulation of land markets using random utility theory based on the work of Anas (1982). The land use model of Santiago (MUSSA) developed by Martínez (1997) is an example of a secondgeneration model.

3. Third-generation models appearing more recently around the second half of the 1990s. These are highly disaggregate models known in some cases as microsimulation models (Iacono et al. 2008). They have a dynamic nature meaning they don't reach complete market equilibrium as the solution to their simulations. One of the better-known models of this type, very widely applied, is URBANSIM developed by Waddell and collaborators at the University of Washington (Waddell et al. 2007).

It is important to note that research is moving forward with the three generations of models and none of them has successfully managed to replace any of the others. Random utility theory is currently the most commonly used paradigm in location choice modeling for different urban agents. This theory has, to a large extent, substituted the location models based on spatial interaction theory, which offered a smaller behavioral base even though various researchers have shown that both approaches may provide similar results under certain assumptions (Anas 1983).

In the field of simulating the transport subsystem, LUTI models have sometimes been criticized because they incorporate methods which are somewhat distant from the state of the art. Many LUTI models are still based around the classic four stage sequential approach leading some authors to recommend the use of more modern models which could be either endogenous or exogenous to the rest of the LUTI simulator (Wegener 2004).

The ability to predict changes in real estate values is an aspect of LUTI modeling that has received increased interest for evaluating and financing planning policies and public projects. However, real estate prices are not predicted by all the models, and when they are, the predictions are not all based on the same procedures. The techniques that agree most with established economic theory are those that predict the prices of the different properties based on a system of market equilibrium. The MUSSA model developed by Martinez (1992) incorporates a bid-choice system of modeling similar to that proposed in the theory of Alonso with the inclusion of a stochastic component derived from random utility theory. Other models have applied hedonic regression techniques based on the market simulation of heterogeneous goods formalized after the work of Rosen (1974). This type of model uses multiple regression to estimate variations in real estate prices and represents the envelope function of the functions of supply and valuations of producers and consumers. The estimated prices depend on a series of structural attributes related to the properties themselves as well as to other environmental and location characteristics. This class of models is able to exogenously estimate prices, in other words, by only taking into account property characteristics specified using external data to the model, or endogenously, by simulating a supply and demand mechanism derived from measures of an area's location capacities and the number of agents willing to locate there (Coppola and Nuzzolo 2011).

\section{Description of the Integrated Models System}

\section{General Structure}

The main purpose of the LUTI model presented in this article is to estimate variations in the location of population, employment, and property prices in an urban system when faced with changes that are mainly associated to the transport system, such as the introduction of new transport modes or new travel demand management policies.

The system developed here can be framed between the first- and second-generation models in the classification presented in the section "Bibliographic Review." It combines traits derived from the spatial interaction models, especially the Lowry type, including the distinction between basic and nonbasic activities, with the inclusion of random utility theory in the simulation of household and economic activities location decisions. The model is also able to simulate average zonal real estate prices by including an endogenous hedonic pricing submodel. Finally, the integrated system incorporates a connection with a modern transport model, ESTRAUS, which simulates the relationships between the supply and demand of transport with simultaneous equilibrium solution (De Cea et al. 2003). This allows the model to consistently simulate urban systems with the presence of congestion.

The integrated system is made up of four interrelated submodels. The interaction between the submodels is solved through an equilibrium solution, meaning the model could be characterized as a comparative equilibrium model. This allows for any change occurring in the territorial system to lead to a new equilibrium solution representing the new state of the system. The four submodels making up the main structure of the LUTI model are as follows:

1. A transport model that, given a location pattern for residents and activities, simulates the simultaneous equilibrium between supply and demand in the transport system.

2. A residential location model that, given a journey time between zones, an activity location pattern, a set of real estate prices, and a residential supply, simulates the location of workers and residents in the study area disaggregated by income classes.

3. An economic activities location model that, given each zone's accessibility and the residential location pattern, simulates the distribution of these activities disaggregated by an economic sector.

4. An implicit prices model that, given the structural characteristics of the properties, the environmental characteristics, the demand/supply of location, and the transport conditions of each zone, simulates the property prices.

Depending on the theoretical hypothesis being proposed, multiple interactions and equilibrium problems can occur between the 
different submodels. Firstly, the transport demand in the different zones making up the study area depends on the location of residents and economic activities. This demand involves a series of journey and mode choices that, depending on the available transport supply (network capacity and public transport services), generates a cost matrix between the zones (expressed in either journey times or generalized transport costs) that, in turn, influence the accessibility of each zone.

The implicit prices model calculates the average property prices in each zone as a function of the supply and demand for locating in each zone as well as the structural and environmental characteristics of the area.

The residential location model starts from the hypothesis that workers locate depending on different zonal characteristics, including the distance from workplaces, journey times, or the costs involved, obtained from the interaction between the transport and economic activities location submodels. Another important variable involved in residential location are the property prices of each zone, obtained using the hedonic pricing submodel.

The activity location model works in a similar way to the residential location model, considering the utility of each zone as a function of different variables. Among these variables is the accessibility of the population to each zone, depending on the travel costs between areas derived from the transport model and the population of each zone derived from the residential location model. The flow diagram of the four interrelated submodels can be seen in Fig. 2.

Based on the diagram shown in Fig. 2, the residential and economic activity location models spatially distribute households and companies. These activities (residence, production, consumerism, etc.) attract and generate journeys throughout the different places located in the territorial system that, in turn, are used as input for the transport model during the distribution, modal split, and trip assignment phases. In traditional transport models, the trip generation/ attraction phase is normally considered to be exogenous or could even be calculated from current or planned land use. The use of the LUTI model, which envelopes the household and company location decisions, allows for more consistent estimations to be made on the dynamics of the urban system in reaction to different medium- and long-term planning policies.

The transport model used includes the modal choice phase that is estimated using a logit model. The simulation performed here

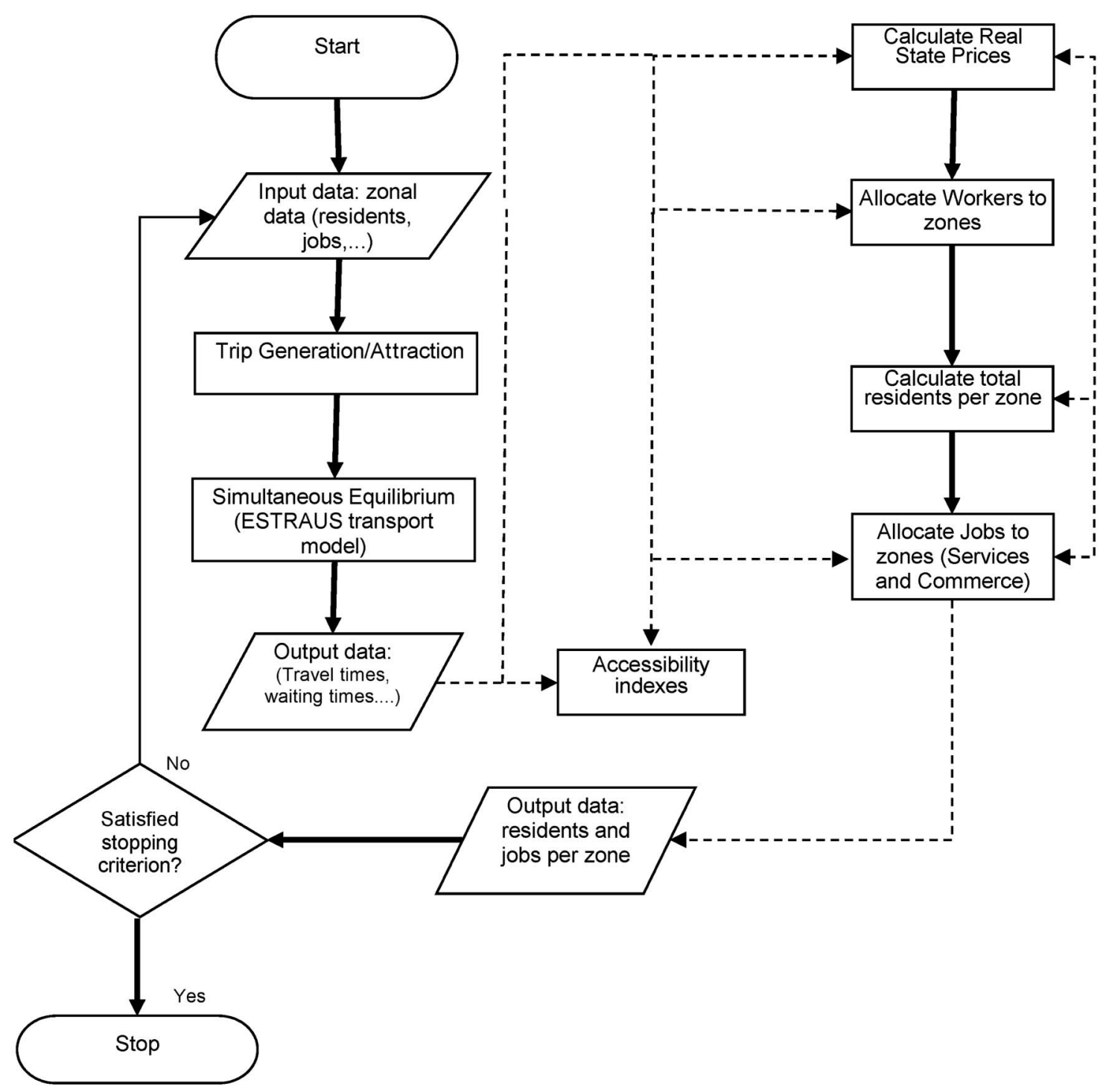

Fig. 2. Flow diagram of the LUTI model 
was based on a choice group of five modes: private transport (car or motorbike), urban bus, light rail, interurban bus, and a combined mode of light rail and urban bus.

Finally, the model as a whole starts from a series of theoretical hypotheses that contribute to the simplification of reality by excluding from the modeling process certain aspects considered secondary or that require data that are difficult to obtain. These hypotheses can be grouped into four basic suppositions:

1. The study area to be modeled is considered "closed" (i.e., the jobs are occupied by the internal demand). From the modeling point of view, closing the territorial system avoids problems associated with worker immigration/emigration and commuter movements outside the study area. On the other hand, this assumption might lead to neglect the impact long-distance commuters (those employed in the study area and residing outside of it, e.g., in other municipalities) have on the transport system being studied. To limit the drawbacks of such an assumption, the study area should be metropolitan in nature and not exclusively local or municipal. In other words, it should include all the residential areas and municipalities where people working in the study area reside. For instance, it has been verified in the application presented in the section "Transport Model" that the labor force within the metropolitan area of Santander covers about the $97 \%$ of the jobs in the study area. This makes the assumption of "closed" study area largely acceptable, since the percentage of long-distance commuter trips over the total home-to-work demand is negligible. For the sake of completion, it must be said, however, that there could be cases in which this assumption does not hold, such as the case of some U.S. and European metropolises (served by high speed railway and/or big airports) where people daily commute between cities at distances of hundreds of kilometers (i.e., the so-called phenomenon of super commuting). In these cases, since it is not possible to enlarge the study area to such a great extent, an economic model simulating the migrations between different cities on a national or international scale should be adopted [see for instance the regional model within the DELTA package by Simmonds (2001)].

2. The real estate supply is considered fixed in the study area (i.e., the proposed model does not present any property supply submodel).

3. The location of basic sector activity is exogenous to the model following the economic base theory implemented in the Lowry model (Lowry 1964). Basic sector economic activities are assumed to locate without taking into account the distribution of the population in the study area because they do not directly depend on the internal demand. The distribution of this type of employment can therefore be considered as fixed or change only because of external considerations to the working of the model.

4. There are no explicit capacity constraints on the location of economic activities and population. Although in principle this assumption allows the number of people living in a zone to exceed the housing capacity of that zone, this is unlikely in a practical application if the parameter of the housing demand and supply ratio (i.e., the attribute $D S(o)$ in the real estate price model) is correctly calibrated. In fact, when the demand for housing in a given zone approaches capacity, the ratio between residential demand and supply ratio [i.e., $D S(o)$ ] increases, leading the price of the houses in zone " $o$ " to such a high value that it makes the probability of additional demand in the zone equal to zero. This is the same dynamic that arises in the traffic assignment equilibrium on road networks, when no explicit link capacity constraints are included in the model, but the link cost is a function of the flow-capacity ratio [e.g., through a Bureau of Public Roads (BPR) function]. In other words, when the parameter of the attribute DS is properly calibrated, the capacity constraint is respected, unless the total housing demand in the study area exceeds the total housing supply. On the other hand, from the mathematical point of view, the assumption allows us to prove there is a unique solution to the equilibrium problem of the spatial distribution of residents and economic activities (see Nuzzolo and Coppola 2005).

\section{Transport Model}

The transport model is briefly summarized because it does not form part of the main goal of this article, which is more focused on the simulation of land use; however, as mentioned earlier, the integrated system incorporates the ESTRAUS transport model (De Cea et al. 2003).

After receiving the input data on population and activity patterns, the transport model can simulate the generation, distribution, modal split, and assignment of journeys. The transport model can, in turn, provide input data for the land use models based on travel costs by transport mode between zones and average waiting times in each area, among others. ESTRAUS uses a deterministic equilibrium model based on Wardrop's first principle for the route choice model and a hierarchical logit model for the other travel choices. In addition, ESTRAUS allows simultaneous equilibrium between transport supply and transport demand, which refers to consistency in the levels of services and transport flows in each step of the model.

As the equilibrium between transport supply and demand is provided by ESTRAUS the accessibility indicators can be calculated, representing the fundamental link between the transport and land use subsystems. From a theoretical point of view, accessibility has been defined as the ease by which any activity can be reached from a given location using a transport system (Geurs and van Wee 2004). Handy and Niemeier (1997) classify the measures of accessibility into three large groups:

- Measures based on accumulated opportunities: These are taken from two points of view depending on whether the opportunities are measured from either the demand or supply centers. In the first instance, they quantify the possibility of reaching a goal within a given area measured in journey time or distance (potential supply). In the latter, they measure the population size within the spatial reach of the equipment or service (potential demand).

- Measures based on gravity models: These refer to the capacity of a place to reach certain opportunities, generally weighted by distances or journey times. This can also be expressed as a place's capacity to be reached from other places generally weighting the population of the nearby zones by the journey times or distances they have to make.

- Measures based on random utility theory: These have a more disaggregate nature and evaluate the desirability of a set of destinations (i.e., the denominator of the multinomial logit model or logsum).

In spite of the many theoretical studies carried out and the wide range of available indicators, in the applied field and especially in Europe, there has been a lack of applications that have evaluated the impact of changing accessibility conditions in urban systems. Because of its greater ease in calculation and interpretation, a gravity indicator was chosen to measure accessibility in each of the zones in the metropolitan area. The accessibility of a zone can be 
split into two large subtypes. They are denominated as active accessibility or the potential reachable opportunities from an area, and passive accessibility or the potential of consumers able to reach the activities taking place in an area (Cascetta 2009).

The active accessibility of a determined zone to the employment opportunities in the rest of the zones can be calculated using the following expression:

$$
\operatorname{Acc}(o)=\sum_{i}\left\{\exp \left[\alpha_{2} \cdot \operatorname{Cost}\left(o, d_{i}\right)\right] \cdot \operatorname{jobs}\left(d_{i}\right)^{\alpha_{1}}\right\}
$$

where Cost $=$ a measure of travel cost by transport mode between origin $o$ and destination $d_{i}$, Jobs $\left(d_{i}\right)=$ the number of jobs in destination zone $d_{i}$, and $\alpha_{1}$ and $\alpha_{2}=$ the parameters to be estimated. Passive accessibility can be represented by

$$
\operatorname{Acc}(d)=\sum_{i}\left\{\exp \left[\beta_{2} \cdot \operatorname{Cost}\left(o_{i}, d\right)\right] \cdot \operatorname{res}\left(o_{i}\right)^{\beta_{1}}\right\}
$$

where Cost $=$ a measure of travel cost by mode of transport between origin $i$ and destination $d$, res $\left(o_{i}\right)=$ the number of residents present in origin zone $o_{i}$, and $\beta_{1}$ and $\beta_{2}=$ the parameters to be estimated. Various measures of cost can be used, including travel times and expressions of generalized cost. Expressions (1) and (2) can also be calibrated by linearizing the expressions through a logarithmic transformation. As the transport model is multimodal, it considers public transport and the relative variables separated by mode.

\section{Residential Location Model}

The main aim of the residential location model is to calculate the number of residents that live in each of the zones in the study area. A similar model to the one presented in this article has been proposed by Hsu and Guo (2006). The model is based on a hypothesis derived from random utility theory that individuals choose locations that maximize their utility. As the modeler cannot know, in an absolute way, how individuals value different locations, a probabilistic discrete choice model is postulated in which the error terms are assumed to be independently and identically distributed Gumbel. The consumers of residential spaces value different zones as a function of their environmental and location attributes relative to their places of work, among other factors. Using these assumptions, the probability that workers of type $i$ (income class) choose zone $o$ as their place of residence conditioned to working in $d$ is given by the following well-known logit type formulation

$$
P_{\text {res-cond }}^{i}(o \mid d)=\frac{\exp \left[V^{i}(o \mid d)\right]}{\sum_{o} \exp \left[V^{i}(o \mid d)\right]}
$$

where $P_{\text {res-cond }}^{i}(o \mid d)=$ the probability of a type $i$ worker choosing to live in zone $o$ conditional on working in zone $d$ and $V^{i}(o \mid d)=$ the systematic utility given to type $i$ worker choosing to live in zone $o$ conditional on working in zone $d$. Under assumption 1, previously mentioned, the study area is a closed labor market. Therefore, the supply of employment is taken up by the internal demand of employees. From this hypothesis, it can be deduced that the number of workers $w$ of type $i$ who locate in zone $o$ is equal to

$$
w^{i}(o)=\sum_{d} P_{\text {res-cond }}^{i}(o \mid d) \cdot \operatorname{Emp}^{i}(d)
$$

where $\operatorname{Emp}^{i}(d)=$ the total number jobs in zone $d$ available to class $i$ workers.

Finally, knowing the number of workers in each zone of the study area allows us to find the total number of residents in the zone by using the coefficient $k(o)$ representing the ratio between residents and workers in each zone:

$$
\operatorname{res}(o)=k(o) \cdot \sum_{i} \sum_{d} P_{\text {res-cond }}^{i}(o \mid d) \cdot \operatorname{Emp}^{i}(d)
$$

Expression (5) can now be used to calculate the number of residents who locate in each zone within the proposed hypotheses. The number of residents depends on the number of jobs in zones $d$, which is consistent according to economic base theory in assuming that any increase in employment has multiplying effects on the population of the urban system.

\section{Economic Activities Location Model}

The economic activities location model can be used to determine the distribution of employment in the different zones of the study area disaggregated into sectors. The basic expression of the model is

$$
\operatorname{Emp}_{a}(d)=P_{a}(d) \cdot \operatorname{EMP}_{a}
$$

where $\operatorname{Emp}_{a}(d)=$ the number of jobs located in zone $d$ belonging to sector $a, P_{a}(d)=$ the probability that a type $a$ job is located in zone $d$, and $\operatorname{EMP}_{a}=$ the total number of type $a$ jobs in the study area. In a similar way to the residential location model, random utility theory is used to simulate the activity location decisions by modeling the decisions as discrete choices. The private agents are assumed to assign a utility to each zone and choose the one that returns the maximum utility. The utility is again assumed to be made up of two parts: systematic and random. If these residuals are independently and identically distributed Gumbel, the probability $P_{a}(d)$ of locating the activity in zone $d$ is given by

$$
P_{a}(d)=\frac{\exp \left[V_{a}(d)\right]}{\sum_{d} \exp \left[V_{a}(d)\right]}
$$

The model is able to differentiate between activities. In urban modeling research, these are generally classified into four categories (Nuzzolo and Coppola 2005):

- Basic sector activities dependent on exporting outside the system and therefore with location not directly tied to the distribution of internal demand (i.e., to the location of households or other economic activities).

- Activities aimed at the internal demand such as retail and nonadvanced services that depend on the location of the demand.

- Representative activities such as those whose location depends on particularly attractive zonal characteristics for reasons of prestige or centrality.

- Activities with low spatial efficiency that need large areas of land to function correctly such as car dealerships and industrial complexes.

The economic activity location model used in the integrated modeling system considers only those activities where the location depends on the population distribution, in other words, activities aimed at the internal demand considered by economic base theory to belong to the nonbasic sector. The classification of activities as belonging to the basic or nonbasic sector has received various criticisms (Camagni 2005). Even so, it may be considered a valid approximation in models that do not seek long-term forecasting of the impact of an expansion of the demand in the base sector in the amount of population and employment of the study area (as is the present case).

Because residential location depends on the location of economic activities and vice versa, an equilibrium problem for both is presented. Mathematically it can be formularized in the following way: 


$$
\begin{cases}R^{i}=R\left[\sum_{i} A^{i}\right] & \forall i \\ A^{i}=A\left[\sum_{i} R^{i}\right] & \forall i\end{cases}
$$

where $R^{i}=$ a vector $\left[n_{-}\right.$zones $\left.\times 1\right]$ of type $i$ residents and $A^{i}=$ a vector [ $n_{-} z o n e s \times 1$ ] of total type $i$ jobs. The solution to this equilibrium problem can be treated as a fixed point problem with its solution given by the vectors $R^{i *}$ and $A^{i *}$. The existence of this equilibrium solution comes from the fulfillment of the conditions imposed by the Brouwer's theorem (Cascetta 2009). The uniqueness of the solution can be checked if the functions $R[\cdot]$ and $A[\cdot]$ are strictly monotonous and the probabilistic location model is additive (as in the case of the logit model).

\section{Real Estate Price Prediction Model}

The property price simulation model is based on the theory of hedonic regression formalized from the new consumer theory of Lancaster (1966) and, above all, based on the theory of market functioning for heterogeneous goods developed by Rosen (1974). This methodology has been shown to give good results when simulating variations in real estate prices caused by changes in transport or environment conditions [see for example Smith and Gihring (2006) in the case of transport and Nelson et al. (1992) and Zeiss (1990) in the case of environment]. In addition, the hedonic model has been specified as endogenous (i.e., zonal housing prices are also affected by the location choices of agents).

Because the LUTI model as a whole simulates the urban system as a discrete space, the hedonic regression needs to be estimated based on the aggregation of the variables in the database. The general structure of the model is as follows:

$$
\ln P_{j}(o)=\beta_{0}+\beta_{1} X_{j 1}(o)+\cdots+\beta_{n} X_{j n}(o)+\gamma_{o}\left(\frac{D_{j}(o)}{S_{j}(o)}\right)+\varepsilon_{j}
$$

where $P_{j}(o)=$ the average price of the group of properties type $j$ in zone $o ; X_{j n}(o)=$ an attribute of the properties type $j$ in the zone $o$ or of its environmental characteristics; $D_{j}(o)=$ the real estate demand for properties type $j$ in the zone $o ; S_{j}(o)=$ the real estate supply of properties type $j$ in the zone $o ; \beta_{1}, \beta_{2}, \beta_{n}, \gamma_{0}=$ the parameters to be estimated; and $\varepsilon_{j}=$ an identically distributed independent error term between observations.

The specification of the hedonic model shows a semilogarithmic functional form (i.e., the value of each estimated parameter represents the semielasticity). This functional form is one of the more commonly used in applied studies because the value of the coefficient is easier to interpret and it has the added advantage of reducing problems associated with heteroscedasticity (Malpezzi 2008). Nevertheless, the specialized literature does not provide any consensus about which functional form is the most appropriate because theoretically there are no restrictions (Cropper et al. 1988; Stephen 1999).

\section{Application of the Model to the Metropolitan Area of Santander}

\section{Introduction to the Area and the Data Used}

The integrated system of models developed in this work will be applied to the metropolitan area of the city of Santander located in the north of Spain. Santander is a medium-sized town and the administrative capital of the region of Cantabria. The city itself currently has a population of 182,700 inhabitants, which rises to 280,000 for the larger metropolitan area. The overall area provides around 100,000 jobs, of which 67,000 correspond to the capital. The population and the employment are highly concentrated in the city of Santander and along the axis formed by other important urban centers within the metropolitan area such as Astillero (10,020 hab.), Muriedas (11,279 hab.), and Maliaño (5,272 hab.) (see Fig. 3). Santander is connected to the other relevant centers by various transport networks and transport services. These networks are mainly made up of urban and interurban roads with their associated public transport services as well as the suburban railway network that connects the most important centers of population within the study area.

The area is administered by nine different municipal boroughs. The zoning used in this study has divided the metropolitan area into 42 zones (see Fig. 3). The different submodels will be calibrated with data from 2008, which is taken to be the base year for this research.

The data used in estimating the parameters of the different submodels came from three main sources. The first source was provided by official statistics. The Spanish Institute of Statistics publishes the Population and Household Census and annual municipal registers that provide data on the location and characteristics of the population and households per census district. These data have been used for estimating the residential location models. The Institute of Regional Statistics publishes the Regional Company Directory for 2008, which contains information on the location and characteristics of individual economic activities (number of employees, classification by sector, etc.). These data have been used in estimating the location models for economic activities. The data for estimating the real estate pricing model has come from two real estate sources given that the required detail of disaggregated data does not exist in the study area. Finally, the third data source used consisted of a transport survey designed by the authors and others that provided information on the characteristics of the surveyed households and the mobility of each household member.

The data required to run the transport model is imported through a series of text files that can be edited before each simulation cycle. In the present case, the zonal trip generation/attraction archive is modified at each iteration depending on the results provided by residential and company location submodels. These submodels were programmed using MATLAB code. An initial procedure imports the results of the transport costs between the zones and calculates the accessibility indicators. A second phase then calculates the real estate price indices as well as the distribution of households and companies through the location models. Finally, these data are once again input into the ESTRAUS software, which calculates the trip generation and attraction along with the rest of the stages involved in the transport model.

\section{Accessibility Indicators}

The calibration of the accessibility indicators must be carried out by previously linearizing expressions (1) and (2) taking logarithms to both sides of the equation. The parameters can later be estimated using ordinary least squares (OLS). This type of estimation implies the use of a dependent variable that can be interpreted as a proxy for the accessibility conditions of each zone. This study has taken the proxy variable to be the transport flows generated and attracted by each zone in the base year as the active and passive accessibility indicators, respectively. This interpretation means that the more journeys that are generated or attracted by a zone then the greater will be its active and passive accessibility conditions. The cost 


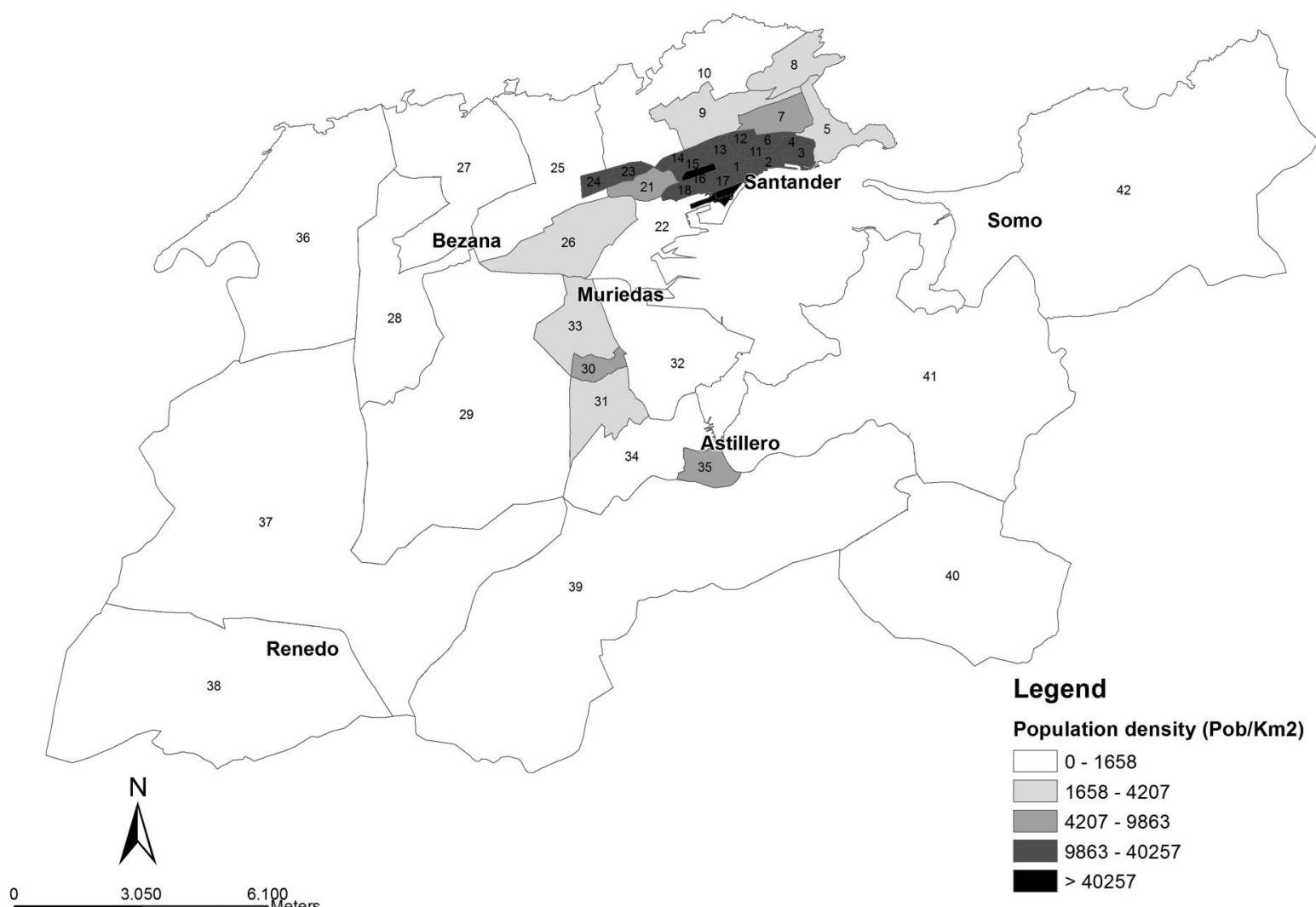

(a)

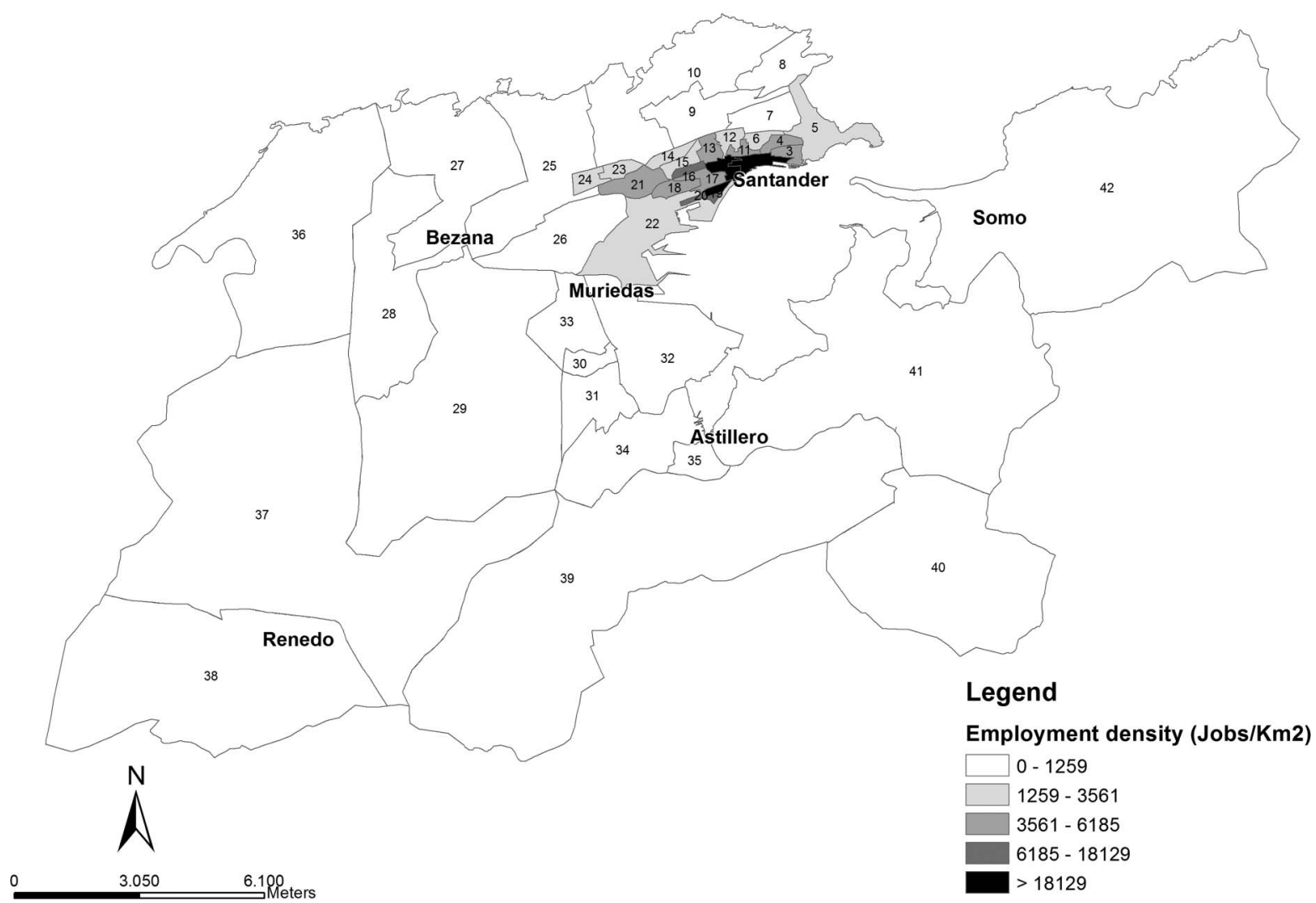

(b)

Fig. 3. Zoning the study area 
Table 1. Estimation of the Parameters of the Accessibility Indicators

\begin{tabular}{lrcrrr}
\hline & \multicolumn{2}{c}{ Active accessibility } & & \multicolumn{2}{c}{ Passive accessibility } \\
\cline { 2 - 3 } \cline { 5 - 6 } Variable & \multicolumn{1}{c}{$\beta$} & $p$-value & & $\beta$ & $p$-value \\
\hline Ln_Jobs/Ln_Res & 0.265 & 0.000 & & 0.269 & 0.000 \\
Cost & -0.120 & 0.000 & & -0.195 & 0.000 \\
$R^{2}$ & \multicolumn{2}{c}{0.64} & & \multicolumn{2}{c}{0.72} \\
\hline
\end{tabular}

variable was obtained using the journey times from the transport model and therefore took congestion into account. The results of the OLS estimation for both indicators are presented in Table 1.

The journey cost parameter in both models was negative, whereas that of opportunities was positive, which is consistent with theory. Furthermore, the magnitude of the parameter of the passive accessibility model was greater, which is also consistent because work-related journeys are known to show lower impedance (Ortúzar and Willumsen 2001). All the parameters were also clearly significant, and although a certain degree of colinearity was detected, this was moderate with VIF values lower than 4 in all cases. Similar fits were found with the parameters for both indicators, although they were slightly better in the case of passive accessibility.

\section{Specification and Estimation of the Residential and Economic Activities Location Models}

The location models for both population and economic activities were disaggregated into two subtypes of agents. The population was divided into two income groups, those with high incomes $(>2,500 €$ available household income) and those with medium and low incomes $(<2,500 €)$. This distinction was made to try to obtain better-fitting parameters for the preferences shown by the different agents. The economic activities belonging to the nonbasic sector were, in turn, differentiated into those specializing in selling goods and those that provided services. The models were specified using the following variables:

- Journey time by mode of transport from home to work, considering congestion, taken from the transport model and expressed in minutes (CT).

- Active accessibility of each zone to employment (ACCA).
- The natural logarithm of the available housing stock (DW).

- The natural logarithm of the average house price in the zone (PRI).

- The prestige of the zone expressed as a dummy variable with a value of 1 if there are positive environmental externalities such as a beach (PG).

- The passive accessibility of each zone with respect to the population (ACCP).

- The basic employment present in the zone, expressed in 1,000 s (EMP).

- The presence of each zone as part of the commercial and business center of the metropolitan area, expressed as a dummy variable with a value of 1 (CBD).

- The characterization of the zone as a highly developed tourist area expressed as a dummy variable with a value of 1 (TOU). The metropolitan system has been divided into four large subareas for the economic activity location models that have been introduced as specific constants in the models. The first of these areas, taken as a reference for the identification of the parameters, is practically the entire municipality of Santander city (zones 1-20, 22-24, and 26). The second constant groups together the zones to the west of Santander that have a high number of retail sector jobs due to the presence of large shopping centers (zones 21 and 25). The third specific constant groups together the zones that are closest to Santander and more strongly integrated into the metropolitan system (zones 27 to 35). Finally, a larger zone that groups together the areas that are less well integrated into the metropolitan system and mainly located in the eastern part of the study area has been defined (zones 36 to 42 ).

The location model parameters estimated using maximum likelihood can be seen in Table 2. The signs of the parameters for the residential location models are in agreement with the theoretical hypothesis. The parameter of the CT variable turned out to be negative in both socioeconomic classes, which is consistent because the model starts from the hypothesis, derived from urban economic theory, that the residents would tend to prefer locations closer to their places of work, ceteris paribus. The parameter for the higher income residents was of a greater magnitude, which reflects a greater disutility of journey time for these users and is coherent with its greater value of time (Glaeser 2008). The DW variable showed a positive sign associated with the greater attraction for the available residential supply. The PRI variable was only significant

Table 2. Parameters Estimated for the Residential and Economic Activities Location Models

\begin{tabular}{|c|c|c|c|c|c|c|c|c|}
\hline \multirow[b]{2}{*}{ Variable } & \multicolumn{2}{|c|}{ Residents, $<2,500$} & \multicolumn{2}{|c|}{ Residents, $>2,500$} & \multicolumn{2}{|c|}{ Jobs-retail sector } & \multicolumn{2}{|c|}{ Jobs-service sector } \\
\hline & $\beta$ & $p$-value & $\beta$ & $p$-value & $\beta$ & $p$-value & $\beta$ & $p$-value \\
\hline $\mathrm{CT}$ & -0.106 & 0.000 & -0.131 & 0.027 & & & & \\
\hline ACCA & - & - & - & - & & & & \\
\hline DW & 1.098 & 0.000 & 0.867 & 0.020 & & & & \\
\hline PRI & -1.541 & 0.000 & - & - & & & & \\
\hline PG & - & - & 0.328 & 0.094 & & & & \\
\hline $\mathrm{ACCP}$ & & & & & 0.643 & 0.000 & 0.206 & 0.004 \\
\hline EMP & & & & & 0.519 & 0.000 & 0.506 & 0.000 \\
\hline CBD & & & & & 1.666 & 0.000 & 1.707 & 0.000 \\
\hline TOU & & & & & -1.189 & 0.045 & 1.430 & 0.000 \\
\hline $\mathrm{K} 2$ & & & & & 2.404 & 0.000 & -0.554 & 0.000 \\
\hline K3 & & & & & -0.412 & 0.009 & -0.083 & 0.425 \\
\hline K4 & & & & & -1.010 & 0.000 & -0.356 & 0.002 \\
\hline $\mathrm{L}(\theta)$ & \multicolumn{2}{|c|}{-776.41} & \multicolumn{2}{|c|}{-235.03} & \multicolumn{2}{|c|}{$-1,234.68$} & \multicolumn{2}{|c|}{$-2,435.89$} \\
\hline $\mathrm{L}(0)$ & \multicolumn{2}{|c|}{$-1,677.91$} & \multicolumn{2}{|c|}{-495.23} & \multicolumn{2}{|c|}{$-4,208.60$} & \multicolumn{2}{|c|}{$-7,475.33$} \\
\hline$R^{2}$ & \multicolumn{2}{|c|}{0.53} & \multicolumn{2}{|c|}{0.52} & \multicolumn{2}{|c|}{0.70} & \multicolumn{2}{|c|}{0.67} \\
\hline $\mathrm{N}$ & \multicolumn{2}{|c|}{515} & \multicolumn{2}{|c|}{152} & \multicolumn{2}{|c|}{1126} & \multicolumn{2}{|c|}{2000} \\
\hline
\end{tabular}


in the case of the residents whose incomes were less than $2,500 €$, whereas the PG variable was only significant for those people with higher incomes at a $90 \%$ confidence level. In both cases, the difference in the significance of the variable according to income would appear to be coherent given that the higher income households could be indifferent to the higher housing costs in certain areas, whereas the prestige factor may not be important for mediumand low-income households taking into account that the estimation data are based on revealed preferences. For both socioeconomic classes, the active accessibility variable showed a parameter that was clearly not significant, which led to its removal from the model. This lack of significance could be due to part of its effects being captured by CT. Even when the residential location model did not incorporate the active accessibility variable, it continued to be sensitive to the costs of the home-work journey, which is an essential characteristic for evaluating policies and projects related to transport. The models had a similar fit for both types of residents using the McFadden's $\mathrm{R}^{2}$ value as the indicator compared with the constants only model.

The parameters had theoretically correct signs in all cases for the economic activities location models. The specific zonal constants were generally negative with respect to the reference, showing that the municipality of Santander has a high location utility probably derived from economies of agglomeration. Only the K2 constant of the retail location model had a parameter with a positive sign because it captured the concentration of jobs due to the presence of large shopping centers. Furthermore, the K3 constant of the service sector location model was not significant although it also had a negative sign. The parameter of the CBD variable had a positive sign and a high magnitude in both models, which highlights the importance of the urban center as an area with a high concentration of nonbasic sector jobs. The dummy variable TOU showed opposing signs in both models probably because highly developed tourist zones have high concentrations of service sector jobs, mainly in catering, while retail development in these areas is much lower. The models had better fits than the residential location models with McFadden $\mathrm{R}^{2}$ values of 0.70 and 0.67 for retail and services, respectively.

\section{Specification and Estimation of the Real Estate Pricing Model}

The implicit prices model was estimated using OLS. In the present application of the model only residential type properties have been considered due to a lack of reliable price data for other typologies. The resulting parameters (see Table 3 ) correspond to the following variables:

- Average dwelling surface area in square meters of the zone (M2).

- Proportion of dwellings with the use of a lift in the zone (LIFT).

- Proportion of dwellings with balcony in the zone (TER).

- Proportion of dwellings with garage in the zone (GAR).

- Average waiting time for public transport in the zone (TESP).

- Interaction between the presence of a bus stop averaging less than $100 \mathrm{~m}$ from the group of properties in the zone and the average number of lines serving the stops in the zone (LIN BUS).

- Active accessibility of the zone (ACCA).

- Distance in minutes to the urban center from the zone centroid (TCBD).

- The presence of each zone as part of the commercial and business center of the metropolitan area, expressed as a dummy variable with a value of 1 (CBD).
Table 3. Parameters Estimated Using the Hedonic Model

\begin{tabular}{lcc}
\hline Variable & $\beta$ & $p$-value \\
\hline (Constant) & 11.713 & 0.000 \\
$M^{2}$ & 0.003 & 0.001 \\
LIFT & - & - \\
TER & 0.013 & 0.000 \\
GAR & 0.005 & 0.000 \\
LIN·BUS & 0.036 & 0.006 \\
ACCA & - & - \\
TCBD & -0.018 & 0.001 \\
TESP & -0.006 & 0.037 \\
CBD & 0.363 & 0.001 \\
BCH & 0.188 & 0.012 \\
PG & 0.830 & 0.000 \\
DS & 0.037 & 0.008 \\
$R^{2}$ & 0.935 & \\
$R^{2}$ adj & 0.913 & \\
\hline
\end{tabular}

- The presence/absence of beach in the zone expressed as a dummy variable with a value of $1(\mathrm{BCH})$.

- The prestige of the zone expressed as a dummy variable with a value of 1 (PG).

- The ratio between residential demand and supply in the zone (DS).

Some of the variables that were originally introduced into the model had to be discarded because of high colinearity, especially between the square meters variable and the average number of bedrooms and bathrooms in the properties of the zone. These latter variables were, therefore, removed from the model because the $M^{2}$ variable is sufficiently explanatory on a zonal scale. The DS variable incorporated into the specification of the models can be calculated using the following equation:

$$
D S(o)=\frac{D(o)}{S(o)} \cdot 100
$$

where $D(o)=$ the number of residents in zone $o$ and $S(o)=$ the number of habitable square meters in zone $o$. This indicator is a measure of the level of occupancy in a zone in the sense of how many residents (demand) are present to each $100 \mathrm{~m}^{2}$ (supply).

The parameters had theoretically consistent signs and were significant at a 95\% confidence level. The LIFT variable corresponding to the proportion of properties equipped with a lift and the ACCA variable corresponding to the active accessibility were removed from the specification because they were clearly not significant. The policy variables, TCBD, TESP, and LIN BUS also proved to be significant and had the correct signs. An increase of $1 \mathrm{~min}$. in the journey time to the $\mathrm{CBD}$ can reduce the average value of properties in a zone by $1.8 \%$ and similarly an increase of $1 \mathrm{~min}$. in average waiting times at the bus stops in a zone could result in an average price reduction of $0.6 \%$. Changes made to available public transport, for example the location of a bus stop at an average of less than $100 \mathrm{~m}$ from the properties in a zone, were shown to have a positive influence on prices by $3.6 \%$ per line serving a stop. The variable DS showed the expected positive sign and was clearly significant. The model's goodness of fit was quite high with a corrected $\mathrm{R}^{2}$ of 0.91 . Two atypical values (outliers) were removed to guarantee the efficiency of the estimators. The chosen selection criteria was that of excluding those cases which showed a residual variable of over 2.5 typical deviations. A Kolmogorov-Smirnov test was applied to check if the model residuals distributed Normal. The test gave a $p$-value of 0.94 so the null hypothesis of Normal residual distribution could not be rejected. 


\section{Goodness of Fit of the Model}

The goodness of fit of the model was evaluated by simulating the base year and the results were compared with those observed from statistical sources. The transport network and flows were modeled using ESTRAUS software, while the overall group of land use models were programmed using MATLAB language. Finally, the routines programmed in MATLAB were connected to ESTRAUS to check the interaction between the transport and land-use submodels. The equilibrium solution between residential location, economic activities location, real estate prices and transport can be found using a simple iterative algorithm after having established a stop criterion. After reaching equilibrium in the transport subsystem, the stop criterion can be set as when the variation between one iteration and the next in the location of population, activities and real estate prices is lower than a predetermined percentage.
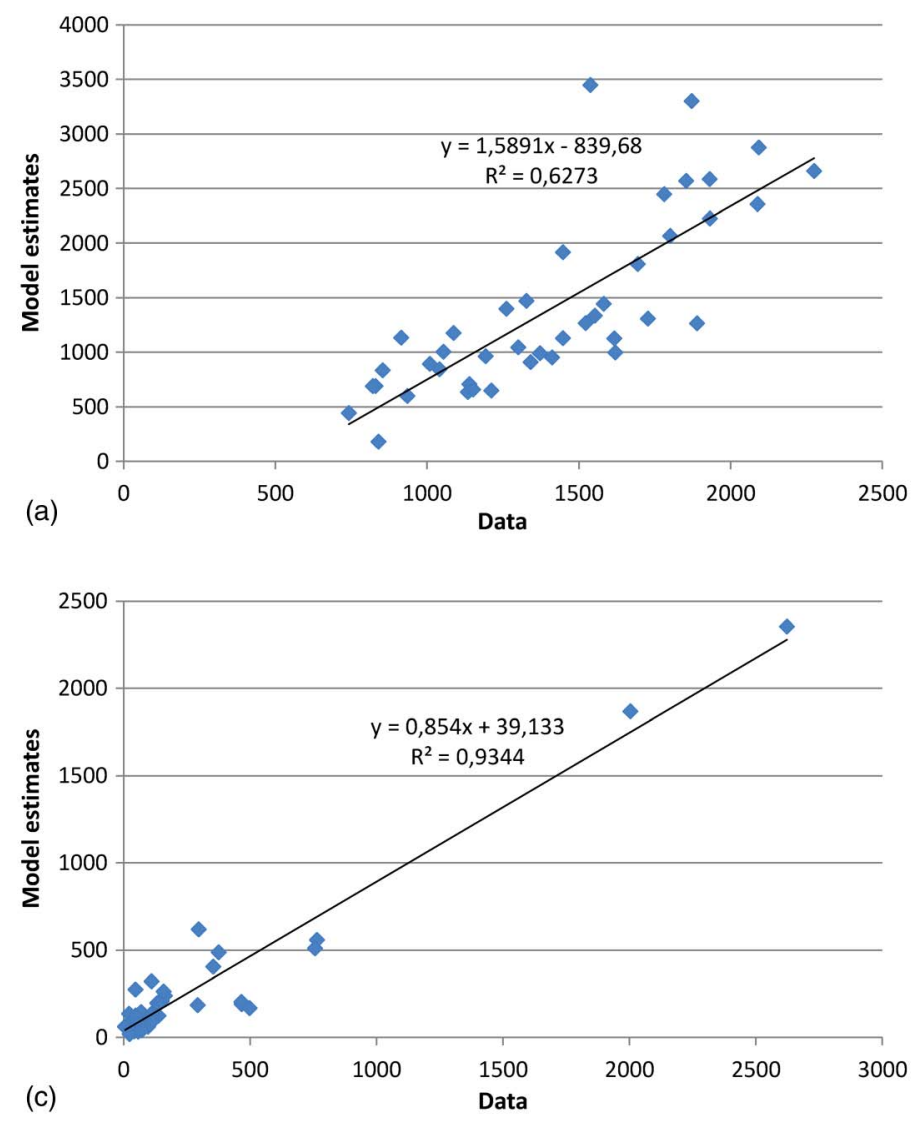

This research established that the variations in the land-use subsystem should be lower than $1 \%$ in each one of the 42 zones making up the overall urban system. The model reached the equilibrium solution relatively quickly after 23 iterations.

According to the $\mathrm{R}^{2}$ test the residential location models showed a fit with the observed population of 0.62 and 0.70 for individuals in households with incomes of more and of less than 2,500€, respectively (see Fig. 4). The models managed to capture the location pattern even though they showed an average absolute error of about $20 \%$.

Turning to the fit of the economic activity location model, the retail activity submodel showed a good fit with an $\mathrm{R}^{2}$ of 0.93 , whereas the service sector location model had a slightly inferior $\mathrm{R}^{2}$ (0.9). The better fit of the retail location model is due to the higher concentration of jobs in this sector mainly found in the city center and areas where large out-of-town shopping centers are
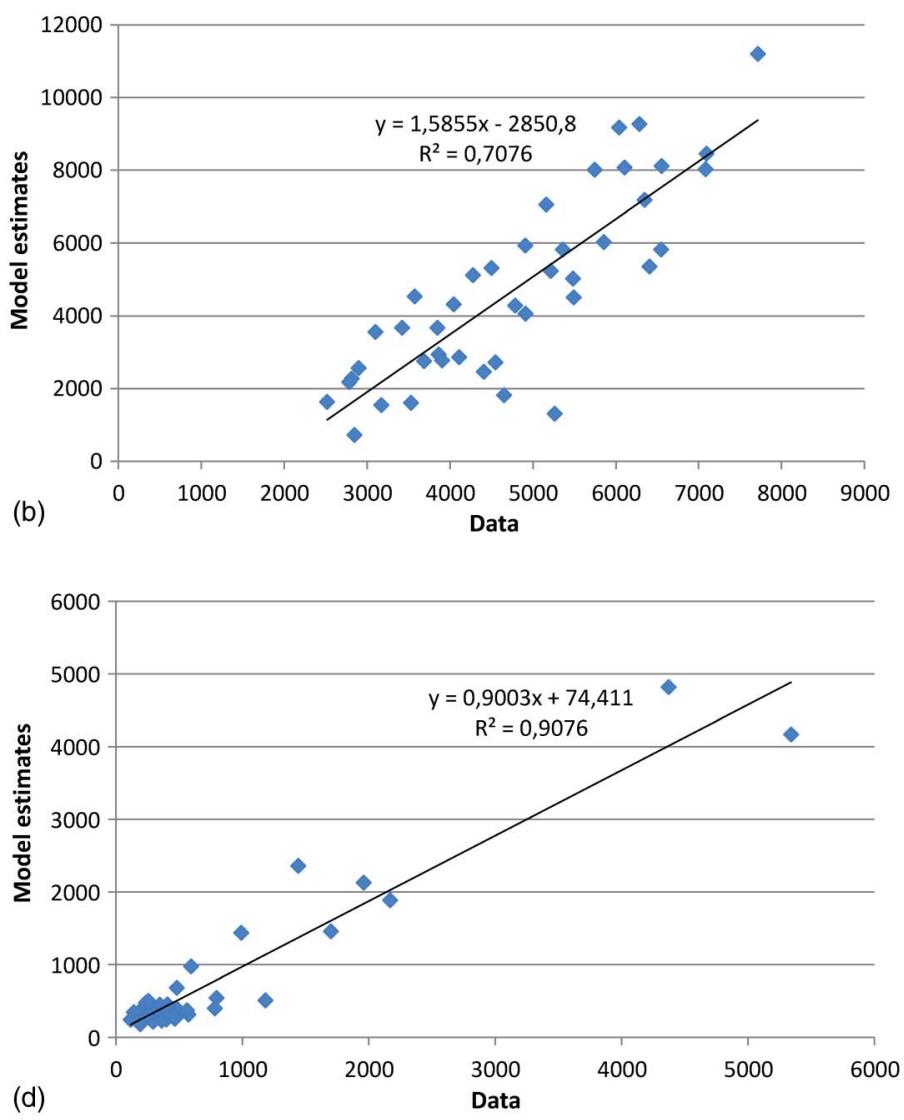

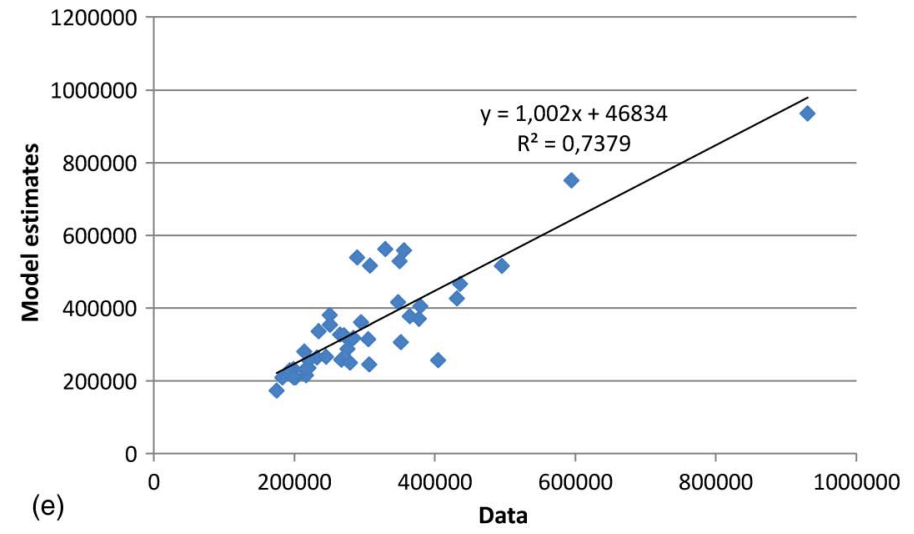

Fig. 4. Estimations of the model versus statistical data for (a) residential location $>2,500 €$; (b) residential location $<2,500 €$; (c) retail sector activity location; (d) service sector activity location; (e) real estate prices 
located, whereas the location of service sector jobs showed that it depended on a greater number of factors showing high groupings at certain specific locations like tourist areas. Overall, the average absolute error for the location of economic activities was around $18 \%$.

Finally, the goodness of fit of the real estate price model had an $\mathrm{R}^{2}$ of 0.79 . The model had greater errors in the zones located further away from the capital where it tended to overstate average property values. The overall average absolute error was slightly lower than that of the economic activities location model, at around $17 \%$.

\section{Conclusions}

This article has presented a land use and transport interaction model that can perform estimations of changes in the location of population, economic activities, and real estate prices as a result of the introduction of policies and projects relating mainly to transport. The model was classified as a LUTI simulator between first and second generation as it combines certain aspects of spatial interaction models with random utility theory and hedonic regression techniques for predicting real estate prices. The model was later applied to the metropolitan area of Santander where its parameters were calibrated and the goodness of fit evaluated using observed data from the base year.

The parameters estimated using the different submodels showed theoretically consistent signs. The travel times from home to work were shown to have an explanatory role in household location, causing more disutility for people with incomes greater than $2,500 €$. Other aspects such as property prices or the prestige value placed on a zone were only significant according to the income levels of the households that also agreed with theoretical expectations. In the case of Santander, the active accessibility of each zone did not prove to have significant weight in explaining residential location, although part of its effects could have been captured by the transport costs. Nevertheless, passive accessibility along with other factors showed significant weight in determining the location of economic activities. The model was also able to demonstrate the importance of Santander and especially the city center, as places where high numbers of jobs are concentrated. The aggregated model of real estate prices showed sensitivity to the available levels of transport services such as waiting times, the number of public transport lines serving an area and the journey time to the CBD by private transport.

The model calibrated as a whole reproduced, to an acceptable level, the spatial distribution of the population and economic activities in the study area as well as the real estate prices in the zones. However, the fit of the model could definitely be improved by further disaggregating the types of households and economic sectors as well as by data collection to allow for more complex specification of the utility functions.

\section{Acknowledgments}

This study was supported by research funding from the Spanish Ministry of Science and Innovation through the Project E 21/08-INTERLAND.

\section{References}

Alonso, W. (1964). Location and land use: Toward a general theory of land rent, Harvard University Press, Cambridge, MA.
Anas, A. (1982). Residential location markets and urban transportation: Economic theory, econometrics, and policy analysis with discrete choice models, Academic Press, New York.

Anas, A. (1983). "Discrete choice theory, information theory and the multinomial logit and gravity models." Transp. Res. B Methodol., 17(1), 13-23.

Andrews, R. B. (1953). "Mechanics of the urban economic base: Historical development of the base concept." Land Econ., 29(2), 161-167.

Brotchie, J. F., Dickey, J. W., and Sharpe, R. (1980). TOPAZ: General planning technique and its applications at the regional, urban, and facility planning levels, Springer, Berlin, New York.

Camagni, R. (2005). Economía Urbana, Antoni Bosch, Barcelona.

Cascetta, E. (2009). Transportation systems analysis: Models and applications, 2nd Ed., Springer, New York.

Coppola, P., and Nuzzolo, A. (2011). "Changing accessibility, dwelling price and the spatial distribution of socio-economic activities." Res. Transp. Econ., 31(1), 63-71.

Cropper, M. L., Leland, B. D., and McConnell, K. E. (1988). "On the choice of funtional form for hedonic price functions." Rev. Econ. Stat., 70(4), 668-675.

De Cea, J., Fernandez, J. E., Dekock, V., Soto, A., and Friesz, T. L. (2003). "ESTRAUS: A computer package for solving supply-demand equilibrium problems on multimodal urban transportation networks with multiple user classes." Annual Meeting of the Transportation Research Board, Washington, DC.

Echenique, M. H. (1994). "Urban and regional studies at the Martin Centre: Its origins, its present, its future." Environ. Plann. B: Plann. Design, 21(5), 517-533.

Echenique, M. H. (2011). "Land use/transport models and economic assessment." Res. Transp. Econ., 39(1), 45-54.

Foot, D. H. S. (1981). Operational urban models: An introduction, Methuen, London, New York.

Fujita, M. (1989). Urban economic theory: Land use and city size, Harvard University Press, Cambridge Cambridgeshire, New York.

Geurs, K. T., and van Wee, B. (2004). "Accessibility evaluation of land-use and transport strategies: Review and research directions." J. Transp. Geogr., 12(2), 127-140.

Glaeser, E. L. (2008). Cities, agglomeration, and spatial equilibrium, Oxford University Press, Oxford.

Handy, S. L., and Niemeier, D. A. (1997). "Measuring accessibility: An exploration of issues and alternatives." Environ. Plann. A, 29(7), $1175-1194$

Harris, B. (1985). "Urban simulation models in regional science." J. Reg. Sci., 25(4), 545-567.

Herbert, J. D., and Stevens, B. H. (1960). "A model for the distribution of residential activity in urban areas." J. Reg. Sci., 2(2), 21-39.

Hsu, C.-I., and Guo, S.-P. (2006). "CBD oriented commuters' mode and residential location choices in an urban area with surface streets and rail transit lines." J. Urban Plann. Dev., 132(4), 235-246.

Iacono, M., Levinson, D., and El-Geneidy, A. (2008). "Models of transportation and land use change: A guide to the territory." J. Plann. Lit., 22(4), 323-340.

Lancaster, K. J. (1966). "A new approach to consumer theory." J. Polit. Econ., 74(2), 132-157.

Leontief, W. (1966). Input-output economics, Oxford University Press, New York.

Lowry, I. S. (1964). A model of metropolis, Rand Corporation, Santa Monica, CA.

Malpezzi, S. (2008). "Hedonic pricing models: A selective and applied review." Housing economics and public policy, T. O'Sullivan, ed., Blackwell Science, Oxford, 67-89.

Martínez, F. (1997). "MUSSA: Land use model for Santiago City." Transport. Res. Rec., 1552(1), 126-134.

Martinez, F. J. (1992). "The bid-choice land-use model: an integrated economic framework." Environ. Plann. A, 24(6), 871-885.

McFadden, D. (1974). Conditional logit analysis of qualitative choice behaviour, P. Zarembka, ed., Academic Press, New York.

Mills, E. S. (1972). Urban economics, Scott, Glenview, IL. 
Muth, R. F. (1969). Cities and housing: The spatial pattern of urban residential land use, University of Chicago Press, Chicago.

Nelson, A. C., Genereux, J. H., and Genereux, M. (1992). "Price effects of landfills on residential land values." J. Urban Plann. Dev., 118(4), $128-137$.

Nuzzolo, A., and Coppola, P. (2005). "S.T.I.T.: A system of mathematical models for the simulation of land-use and transport interactions." Proc. of European Transportation Conference, Association for European Transport, London.

Nuzzolo, A., and Coppola, P. (2007). "Accessibility and socioeconomic activities location." Proc. of European Transportation Conference, Noordwijkerhout, The Netherlands.

Ortúzar, J. d. D., and Willumsen, L. G. (2001). Modelling transport, 3rd Ed., Wiley, Chichester, New York.

Putman, S. H. (1996). "Extending DRAM model: Theory-practice nexus." Transp. Res. Rec., 1552(1), 112-119.

Rosen, S. (1974). "Hedonic prices and implicit markets: Product differentiation in pure competition." J. Polit. Econ., 82(1), 34-55.

Simmonds, D. (2001). "The objectives and design of a new land-use modelling package: DELTA" Regional science in business, G. Clarke and M. Madden, eds., Springer, Berlin, Heidelberg, 159-188.

Smith, J. J., and Gihring, T. A. (2006). Financing transit systems through value capture. An annotated bibliography, Victoria Transport Policy Institute, Victoria, Canada.
Stephen, S. (1999). "Hedonic analysis of housing markets." Chapter 41, Handbook of Regional and Urban Economics, C. Paul and S. M. Edwin, eds., Elsevier, Amsterdam, 1595-1635.

Torrens, P. M. (2000). How land-use transportation models work, Centre for Advanced Spatial Analysis, London.

von Thünen, J. H. (1826). Der isolierte staat in beziehung auf landwirtschaft und nationaloekonomie, Jena. Translated by C. M. Wartenburg (1966). The isolated state, Oxford University Press, Oxford.

Waddell, P., and Ulfarsson, G. F. (2004). "Introduction to urban simulation: Design and development of operational models." Handbook in transport, Volume 5: Transport geography and spatial systems, B. Stopher and H. Kingsley, eds., Pergamon Press, Oxford, 203-236.

Waddell, P., Ulfarsson, G. F., Franklin, J. P., and Lobb, J. (2007). "Incorporating land use in metropolitan transportation planning." Transport. Res. Pol. Pract., 41(5), 382-410.

Wegener, M. (2004). "Overview of land-use transport models." Transport Geography and Spatial Systems, D. A. Hensher and K. Button, eds., Elsevier, Oxford, 127-146.

Wilson, A. G. (1970). Entropy in urban and regional modelling, Pion, London.

Zeiss, C. (1990). "Incinerator impacts on residential property sales. beyond price effects.” J. Urban Plann. Dev., 116(2), 80-97. 